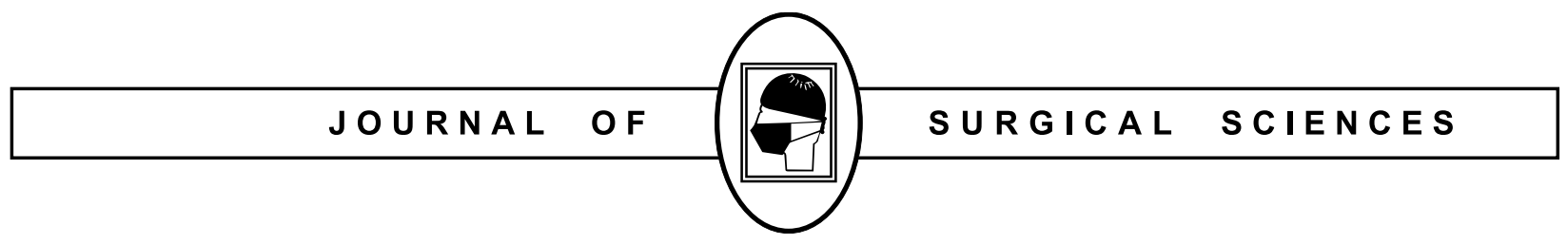

\title{
Editorial
}

\section{BREAST CANCER IN BANGLADESH}

\author{
Parveen Shahida Akhtar \\ Professor of Medical Oncology, National Institute of Cancer Research \& Hospital, Dhaka. \\ Tel: +88-01711622788, e-mail: shanti_oncology@yahoo.com
}

Breast cancer is the most common cancer of Bangladeshi women comprising of $25 \%$ of all female cancers ${ }^{1}$. National Institute of Cancer Research \& Hospital (NICRH) is the largest cancer center of the country, where the cancer patients are referred from every corner of the country. Nine years data of the attending breast cancer patients of this Institution gives an overview of breast cancer patients of Bangladesh.

Since 2008, incidence of breast cancer around the world has increased by more than 20 percent, while mortality has increased by 14 percent $^{2}$. Even though the incidence of breast cancer in developing countries is lower than that in their Western counterparts, it is rising rapidly; comprising of more than half $(52.9 \%)$ are diagnosed in developing countries in $2012^{2}$ while the corresponding figure for 1980 was only $35 \%{ }^{3}$. At $\mathrm{NICRH}$ the reporting of breast cancer sharply increased by $64 \%$ in 2010 since 2008 and the young ladies are found to be the common victims (mean age 42.6 years) ${ }^{1}$. In developed countries breast cancer is mainly a disease of postmenopausal women $(>50$ years) $)^{2}$. The trends of breast cancer occurrence in Bangladeshi women in younger age group comparing with western countries ${ }^{4}$ have the family history of breast cancer $9 \%$, premenopausal $62 \%$, unhealthy weight (overweight $40 \%$ and obese $27 \%$ )and with comorbid diseases $45 \%{ }^{5}$. Owing to the lack of awareness of this disease and in the absence of a breast cancer screening program, the majority of breast cancers are diagnosed at a relatively advanced stage. Half of the patients (50\%) attended after some sorts of surgery with incomplete information and categorized as unknown stage, $5 \%$ localized cancer (stagel), $15 \%$ regional cancer (stage II) and 30\% comprised of locally advanced stage and or metastatic cancer (stage III \& $I V)^{5}$, just mirror image of SEER result ${ }^{6}$. Women with poor socio-economic status and have none or low educational level are often victims of late presentation and tend to have a higher stage at diagnosis ${ }^{4}$. Left breast was affected more, at a time bilateral breast cancers were uncommon. Infiltrating duct cell carcinoma $(94 \%)$ is the most common histopathological variety; Infiltrating lobular varieties represent only $4 \%{ }^{5}$.

Breast cancer management by multimodal approach improves survival ${ }^{7}$. Average survival of Bangladeshi breast cancer patients is 38.25 months and one year, three years and five years survival rates are $78 \%$, $56 \%$ and $46 \%$ respectively. The result is more or less equivalent to an Indian study ${ }^{8}$, but far away from the developed world ${ }^{6}$. Breast cancer is also a leading cause of cancer death in the less developed countries of the world. This is partly because of a shift in the lifestyles causing an increase in incidence, and partly because clinical advances to combat the disease are not reaching women living in these regions, according to Dr. David Forman, Head of the IARC Section of Cancer Information, the group that compiles the global cancer data ${ }^{2}$.

An urgent need in cancer control today is to develop effective and affordable approaches to the early detection, diagnosis, and treatment of breast cancer.

\section{References:}

1. Cancer Registry report 2008-2010; dept. of Cancer Epidemiology, National Institute of Cancer Research \& Hospital, Dec,2013. 
2. Ferlay J, Soerjomataram I, Ervik M, Dikshit R, Eser S, Mathers C, Rebelo M, Parkin DM, Forman D, Bray, F (2013). GLOBOCAN 2012 v1.0, Cancer Incidence and Mortality Worldwide: IARC CancerBase No. 11 [Internet]. Lyon, France: International Agency for Research on Cancer.

3. Forouzanfar MH, Foreman KJ, Delossantos AM, Lozano R, Lopez AD, Murray CJ, et al. Breast and cervical cancer in 187 countries between 1980 and 2010: a systematic analysis. Lancet 2011;378:1461-84.

4. Rahman M, Ahsan A, Begum F, Rahman K.Epidemiology, Risk Factors and Tumor Profiles of Breast Cancer in Bangladeshi underprivileged women.Gulf J Oncolog. 2015 Jan;1(17):34-42.

5. Akhtar PS1, Khatun N, Masud ZM, Islam MR, Ara F. Breast cancer scenario of Bangladesh: analysis of 7756 cases in nine years, accepted for oral presentation in Bangladesh Cancer Conference 2015 to be held 16-17 November 2015.

6. SEER Cancer Statistics Fact sheets: Female Breast Cancer. National Cancer Institute. Bethesda, MD, http://seer.cancer.gov/statfacts/ html/breast.html

7. Kesson EM, Allardice GM, George WD, Burns HJ, Morrison DS;Effects of multidisciplinary team working on breast cancer survival: retrospective, comparative, interventional cohort study of 13722 women. BMJ. 2012;344:2718.

8. Nandakumar A, Anantha N, Venugopal TC, Sankaranarayanan $\mathrm{R}$, Thimmasetty K, Dhar M. Survival in breast cancer: a population-based study in Bangalore, India. Int J Cancer. 1995;60:593-6. 